\title{
Measurement of RC slab surface shape and investigation of local water stagnation
}

\author{
Yuko Yasuda $^{1 *}$, Ko Kakuma ${ }^{2}$, Yoshitaka Shiroto ${ }^{2}$, and Takashi Matsumoto ${ }^{3}$ \\ ${ }^{1}$ Hokkaido University, Graduate School of Engineering, Kita 13 Nishi 8, Kita-ku, Sapporo, Japan \\ ${ }^{2}$ Civil Engineering Research Institute for Cold Region, Hiragishi 1-3-1-34 Toyohira-ku, Sapporo, Japan \\ ${ }^{3}$ Hokkaido University, Faculty of Engineering, Kita 13 Nishi 8 Kita-ku, Sapporo, Japan
}

\begin{abstract}
In a road bridge, drainage facilities are installed to discharge the water on the bridge surface. For each drainage facility, installation spacings are exemplified by waterproof manuals and others, but the quantitative sharing and drainage capacity of each facility and bridge surface have not been clarified. Also, it is thought that water will be stagnant due to bridge surface irregularities generated during construction or during service. However, no regulations on the concavities and convexities about the slab surface are clearly shown in construction standards. Therefore, in this study, surface shape measurement and water sprinkling test on unpaved actual bridge slab were carried out. From the results, we confirmed the possibility that irregularities on the slab surface affect the tendency of local water stagnation. Since only one bridge was studied in the current study, we have not confirmed the influence of gradient magnitude on the drainage capacity of uneven slab surface. It is a future task to clarify the relation between surface gradient and allowable irregularity size and to develop a standard for controlling irregularities on slab and pavement surface.
\end{abstract}

\section{Introduction}

Drainage of water present on the bridge surface due to rainfall is important for maintenance. Especially if water penetrated from the bridge surface is not drained promptly on the slab surface, degradation of the slab is considered to be promoted.

For this reason, drainage facilities are installed at the bridge to drain water on the bridge surface. For drainage facilities such as catch basins, water pipes, drain holes, installation intervals are exemplified by waterproof manuals and others.

However, quantitative sharing and performance of the drainage capacity of each facility and the drainage capacity of the entire bridge surface are not clarified enough. In addition, some stagnant water may occur on the surface of the slab before reaching the drainage facility. Such partial stagnant water can potentially accelerate the significant deterioration of the slab at that location. Although it is considered that the surface shape of the slab affects the partial water stagnation phenomenon, standards and provisions on the surface shape of the slab related to the occurrence of partial water stagnation are not clearly stated in Road Structure Ordinance and Handbook for Waterproof Roadway Bridge Deck Slabs.

In this study, we measured the surface shape of the slab on an actual bridge and performed the water sprinkling test. From the results, we aim to understand the influence of the shape of the slab surface on the drainage function of the bridge surface.

Table 1. Descriptions of the bridge

\begin{tabular}{|c|c|}
\hline Road standard & 1 st class, 3rd grade \\
\hline Design speed & V=80km/h \\
\hline Structural type & $\begin{array}{c}\text { Simply supported steel } \\
\text { plate composite girder } \\
\text { bridge }\end{array}$ \\
\hline Bridge length & $38 \mathrm{~m}$ \\
\hline Span & $36.4 \mathrm{~m}$ \\
\hline Road width & $19.842 \mathrm{~m}$ to $18.238 \mathrm{~m}$ \\
\hline Curve radius & $2000 \mathrm{~m}$ \\
\hline Skew angle & $80^{\circ} 00^{\prime} 00^{\prime \prime}$ \\
\hline Longitudinal slope & $-0.33825 \%$ \\
\hline Transverse slope & $2 \%$ \\
\hline Design load & B live load \\
\hline
\end{tabular}

* Corresponding author: tautology-sg-yy@eis.hokudai.ac.jp 


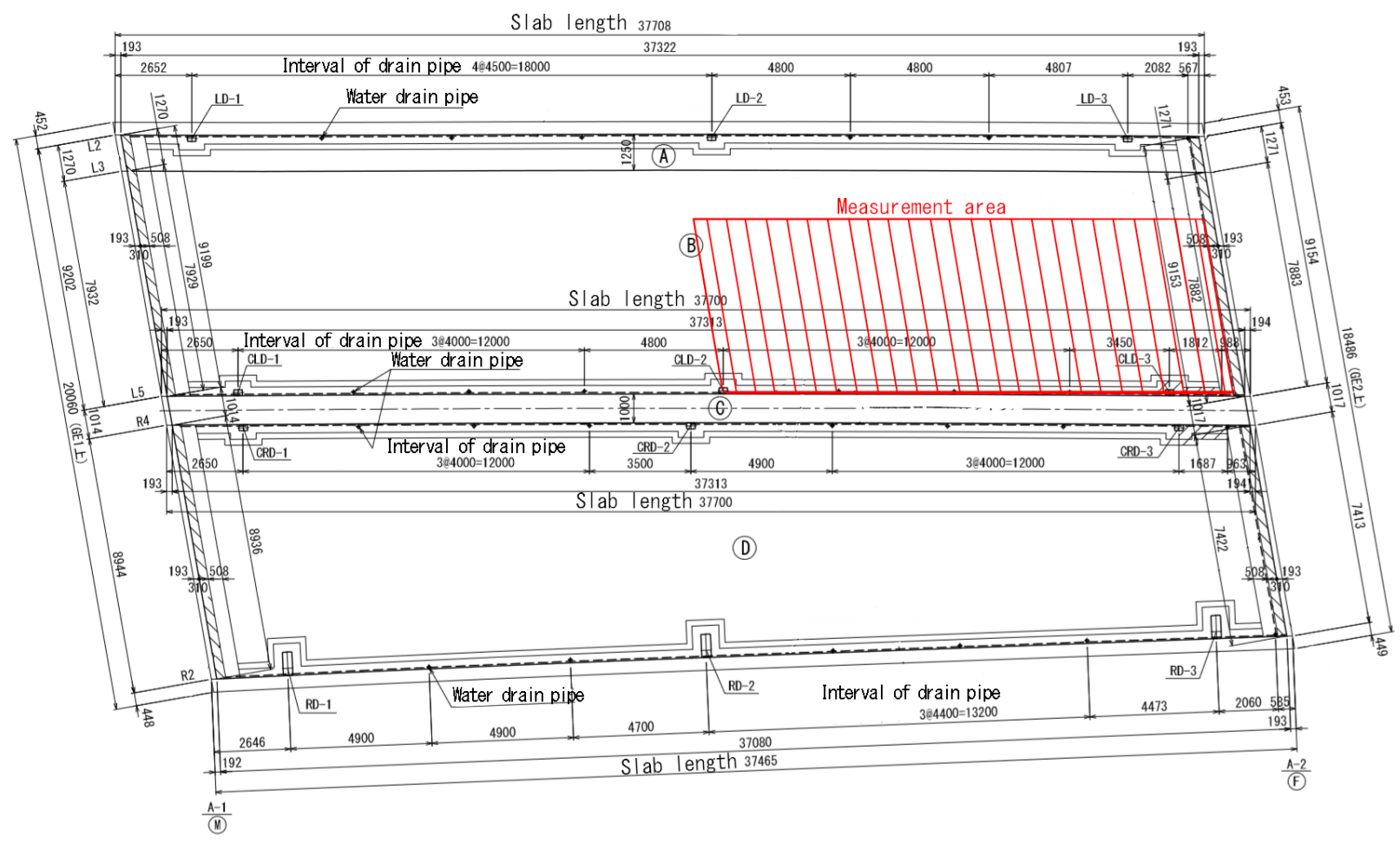

Fig. 1. Bridge plan view

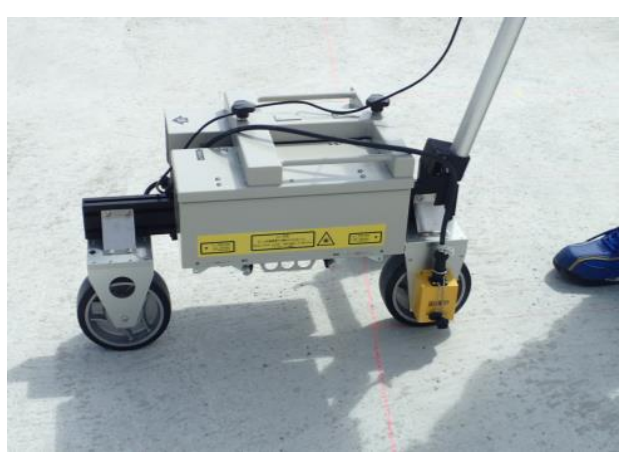

Fig. 2. Measuring equipment (MRP-3000)

\section{Methods}

\subsection{Bridge specifications}

Table 1 shows the specifications of the bridge targeted in this test.

This bridge was before opening its service, and measurements were made before construction of the waterproof layer and pavement. Fig. 1 is the plan view of a target bridge. The measurement area is indicated by red hatching in the figure.

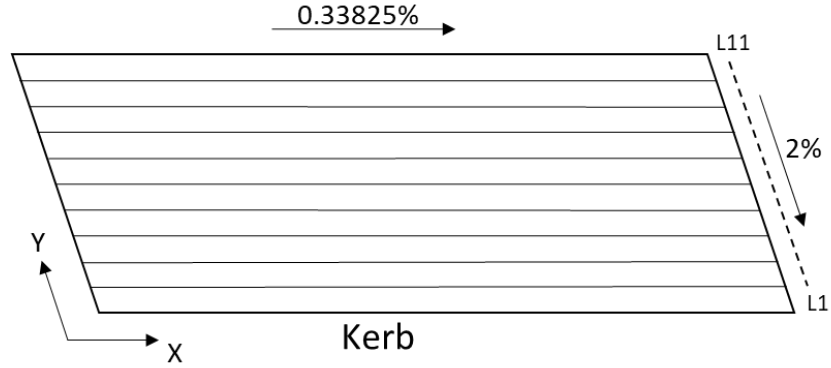

Fig. 3. Measurement lines

\subsection{Measurement}

The measurement area is indicated by hatching in Fig. 1. The area is about a quarter of the L side lane and is $5 \mathrm{~m}$ by $15.47 \mathrm{~m}$. The surface shape of this slab area was measured. Also, water was sprinkled in the same area, and the temporal change of the surface water content was measured.

\subsubsection{Surface shape}


For measuring the surface shape, a tow type road surface property measuring apparatus (Kumataka Engineering Co., Ltd., MRP-3000) was used (Fig. 2).

This device measures the relative height between

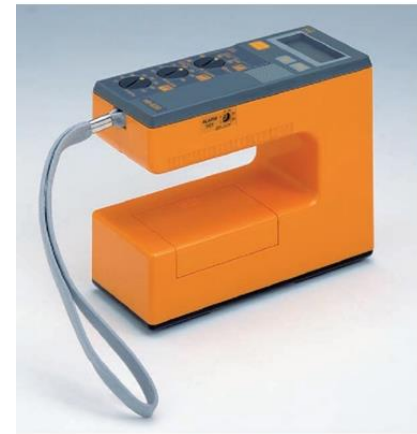

Fig. 4. Measuring equipment (HI-520)

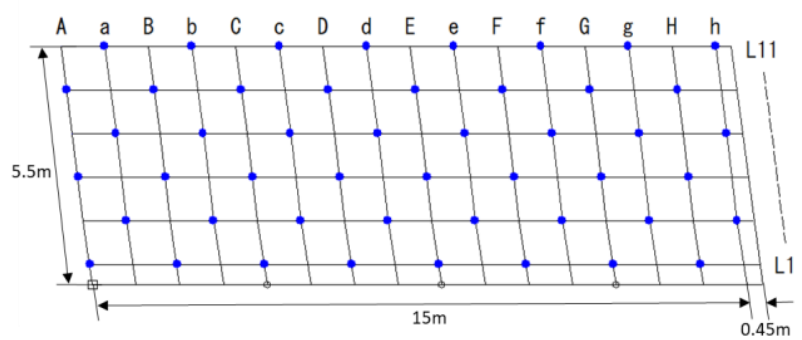

Fig. 5. Measurement points

Table 2. Weather conditions

\begin{tabular}{|c|c|c|}
\hline $\begin{array}{c}\text { Measurement } \\
\text { time }\end{array}$ & Temperature & Humidity \\
\hline $14: 00$ & $26.7^{\circ} \mathrm{C}$ & $48 \%$ \\
\hline $15: 00$ & $24.7^{\circ} \mathrm{C}$ & $67 \%$ \\
\hline $15: 45$ & $22.4^{\circ} \mathrm{C}$ & $77 \%$ \\
\hline
\end{tabular}

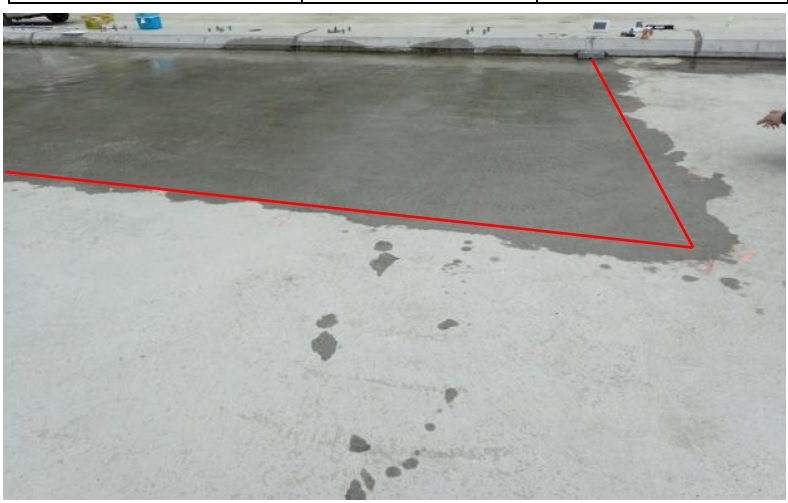

Fig. 6. Water sprinkled area

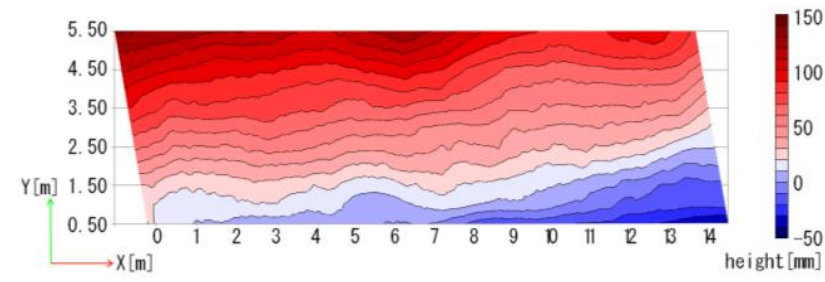

Fig. 7. Contour plot of slab ssurface shape the device and the target surface by laser light. Further, the inclination of the apparatus is measured by a built-in gyro sensor. From these, it is possible to measure irregularities with absolute height.

The measurement was carried out on 11 longitudinal lines with a spacing of $500 \mathrm{~mm}$ in each direction and one transverse line with $\mathrm{X}=0$ (Fig. 3 ).

\subsubsection{Water content}

For water content measurement, a high-frequency capacitive moisture meter (Ket Science Institute, HI520) was used (Fig. 4).

After sprinkling water in the measurement area, change of water content with time on the slab surface was measured. The measurement points were located in a staggered arrangement for the lattice points with their spacing of $1000 \mathrm{~mm}$ in each direction (Fig. 5).

The procedure of the water sprinkling test is explained below.

First, at 12:00, we sprinkled water, a total volume of 40 litres, over the entire measurement area (Fig. 6). The first measurement was carried out at 14:00 which is two hours later after the sprinkling.

Then, 30 liters of additional water was sprinkled to the entire measurement area at 14:30. Second and third measurements were made at 15:00 and 15:45, 30 minutes and 1 hour and 15 minutes after the second sprinkling, respectively.

Table 2 shows the temperature and humidity at the time of measurements.

\section{Results}

\subsection{Surface shape}

From the measurement results for the total of 11 measurement lines, the surface of the slab is shown in the contour plot (Fig. 7). In the figure, the high part is represented by red, and the low part by blue.

\subsection{Water content}

Fig. 8 shows the change of water content after the sprinklings in the measurement area.

Black dots in the figure are measurement positions. Places with high water content are indicated by dark blue, and places with low water content by light blue.

Fig. 9 is a photograph of the slab taken immediately after sprinkling, and Fig. 10 is a photograph taken at 14:00 which is 120 minutes after sprinkling water.

\section{Discussions}

\subsection{Surface shape}

\subsubsection{Longitudinal gradient}




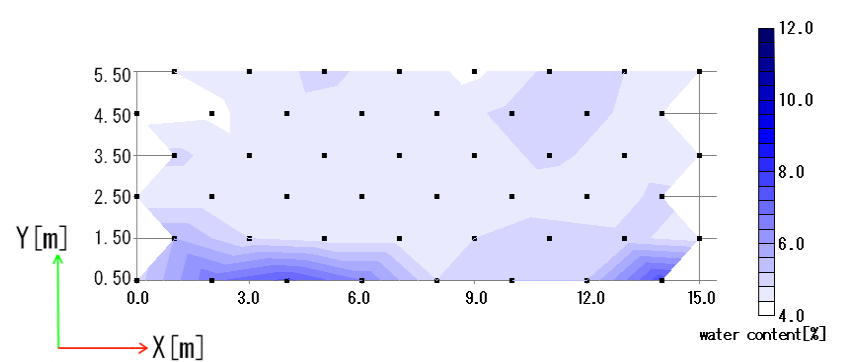

(a) at 14:00

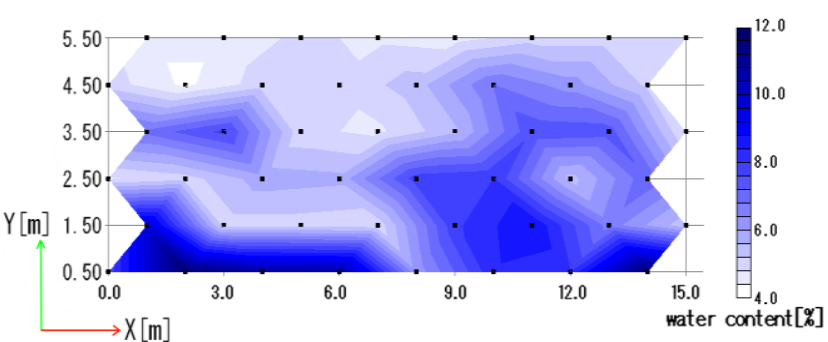

(b) at 15:00

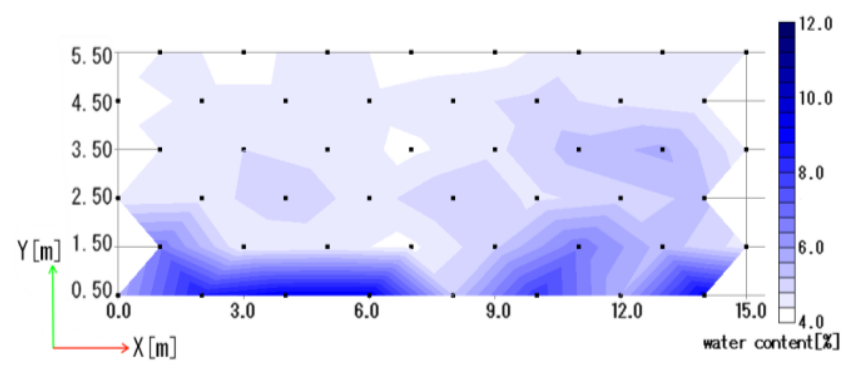

(c) at 15:45

Fig. 8. Water content

For the 11 longitudinal profiles obtained by the surface shape measurement, approximate straight lines were obtained using the least squares method. Table 3 shows the calculation result and the difference between the slope of this approximate straight line (hereinafter referred to as average longitudinal gradient) and the design gradient.

As can be seen from Table 3, the average longitudinal gradient obtained in this measurement was smaller than the design gradient except L1. Also, in Road Structure Order ${ }^{1)}$, it is said that the road surface drainage is sufficiently functional with a longitudinal slope of 0.3 to $0.5 \%$. However, in the survey lines L2 to L10, the average longitudinal gradient was less than $0.3 \%$.

\subsubsection{Characteristics of unevenness}

Next, the difference between the actual measured value of the surface shape and the design slab surface where the transverse gradient and the longitudinal gradient are $2 \%$ and $-0.33825 \%$ are shown in Fig. 11.

As can be seen from the figure, there are several places higher and lower than the design surface in the measurement area. The maximum value of the difference

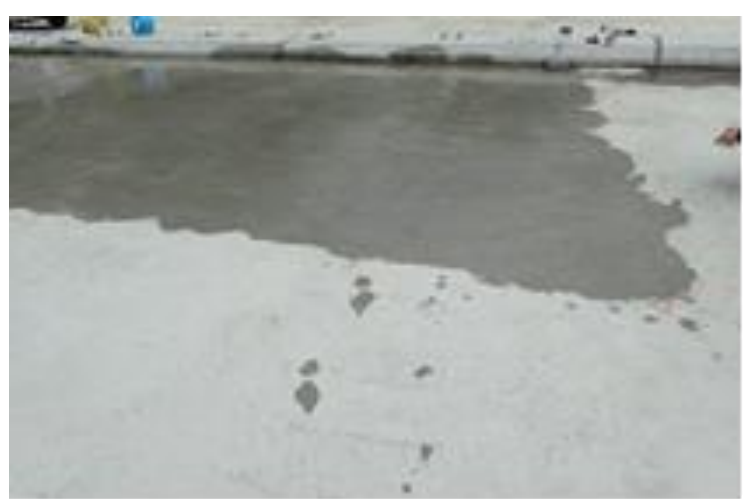

Fig. 9. Immediately after water sprinkling

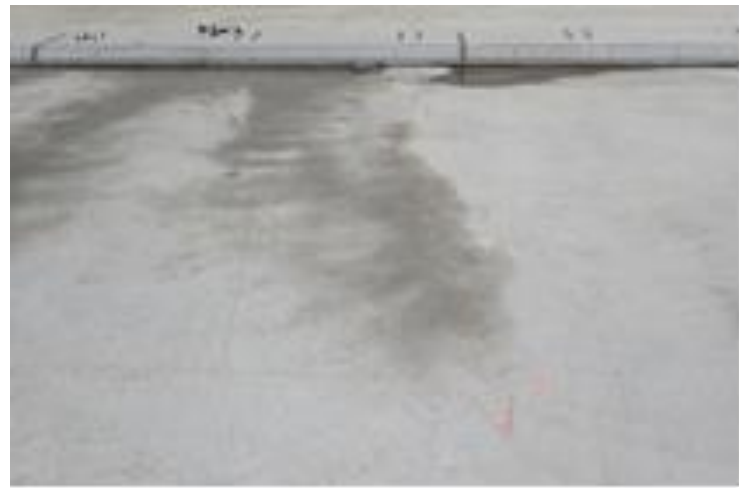

Fig. 10. 120 minutes after water sprinkling

Table 3. Average longitudinal gradient

\begin{tabular}{|c|c|c|}
\hline Line & $\begin{array}{c}\text { Average } \\
\text { longitudinal } \\
\text { gradient (\%) }\end{array}$ & $\begin{array}{c}\text { Difference from } \\
\text { design longitudinal } \\
\text { gradient (\%) }\end{array}$ \\
\hline L1 & -0.3556 & -0.0174 \\
\hline L2 & -0.2388 & 0.0995 \\
\hline L3 & -0.2526 & 0.0857 \\
\hline L4 & -0.2534 & 0.0849 \\
\hline L5 & -0.2678 & 0.0705 \\
\hline L6 & -0.2838 & 0.0546 \\
\hline L7 & -0.2920 & 0.0463 \\
\hline L8 & -0.2770 & 0.0613 \\
\hline L9 & -0.2862 & 0.0521 \\
\hline L10 & -0.2578 & 0.0805 \\
\hline L11 & -0.3052 & 0.0331 \\
\hline Average difference $(\%)$ & 0.0591 \\
\hline
\end{tabular}

from the design slab surface is about $36 \mathrm{~mm}$ at the convex portion and about $15 \mathrm{~mm}$ at the concave portion.

In order to analyze the unevenness characteristics, each of the vertical sectional views of the 11 survey lines is first smoothed by moving average. After that, "top" and "bottom" are extracted from the local maximum point and the local minimum point as shown in Fig. 12. 


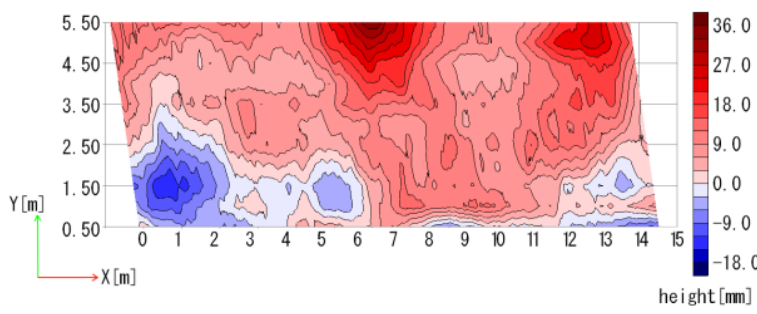

Fig. 11. Difference from design slab surface

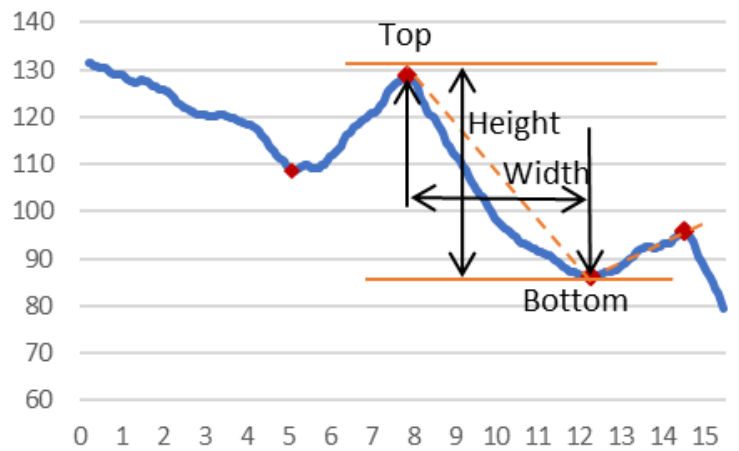

Fig. 12. Definitions related to unevenness

Distance (width), local longitudinal gradient (local gradient) and height difference (height) between neighboring apexes and bottoms are obtained from the distance (width), local longitudinal gradient (local gradient) and height difference (height) between neighboring apexes and bottoms are obtained from the extracted top and bottom. These are shown in the histograms, respectively.

As can be seen from Fig. 13 (a), the height difference between the top and the bottom along the longitudinal direction is mostly within the range of -4 to $7 \mathrm{~mm}$, and secondly within -18 to $-7 \mathrm{~mm}$. As can be seen from Fig. 13 (b), there are few cases with width exceeding $3.5 \mathrm{~m}$. When looking at the whole, it is thought that unevenness within the width of $1 \mathrm{~m}$ contributes to forming irregularities on the surface. There are also a certain number of unevenness having the width of 1 to $3 \mathrm{~m}$. The histogram of the local gradient shown in Fig. 13 (c) has 126 data points. Among them, there are 58 pieces of data as local gradient in the upward direction which may inhibit drainage. Considering Fig. 13 (a) and Fig. 13 (c) together, it is conceivable that many uneven locations with the width of $1 \mathrm{~m}$ or less has the height difference of -4 to $7 \mathrm{~mm}$, and with the width of 1 to $3 \mathrm{~m}$ has the height difference of -18 to $-7 \mathrm{~mm}$.

\subsection{Drainage performance}

The temporal change of local water content has been shown in Fig. 8. A transverse gradient of $2 \%$ is installed

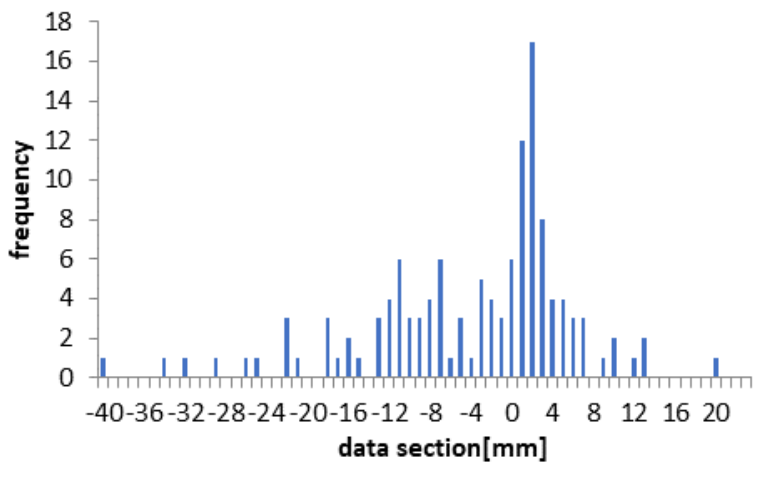

(a) Unevenness height

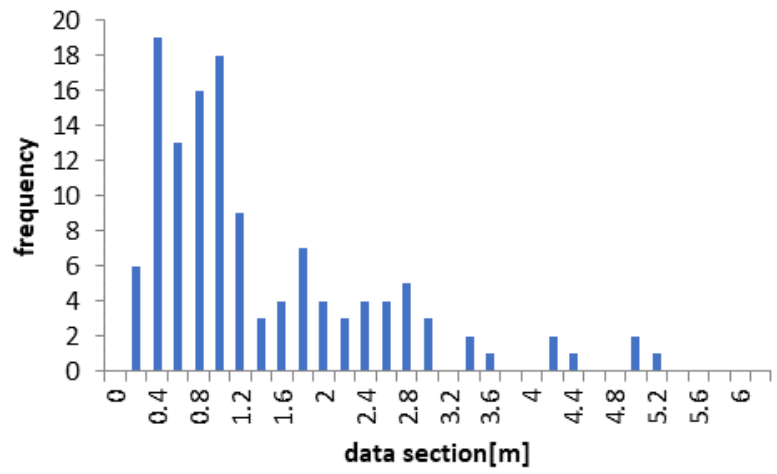

(b) Unevenness width

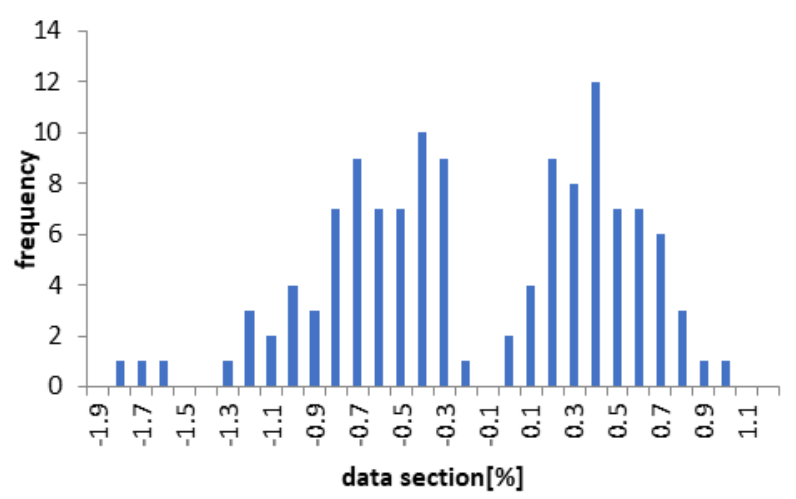

(c) Local gradient

Fig. 13. Histograms about unevenness

in this slab design, and the water content increases at the lower side of the gradient ( $\mathrm{Y}=0.5 \sim 1.5 \mathrm{~m})$.

Especially, paying attention to $\mathrm{Y}=0.5$ which is the end portion, it is understood that the water content tends to increase at the position where drainage does not occur. This indicates that the water arriving at the intersection along the transverse gradient can not be drained in the longitudinal direction. As a result, water tends to accumulate between the drainage devices. This can be a deterioration factor after service. The average longitudinal gradient of L1 on the kerb side satisfied the 


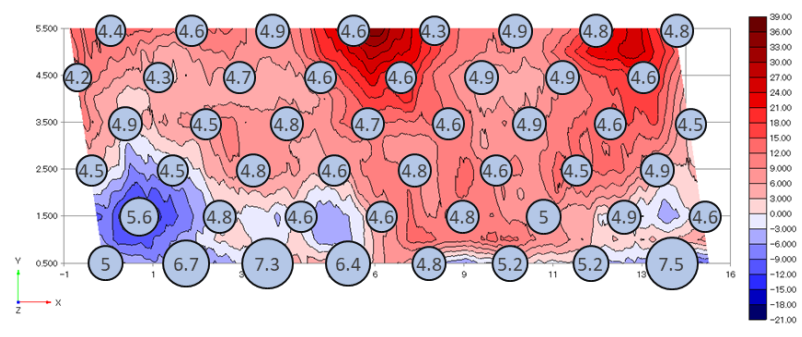

(a) at 14:00

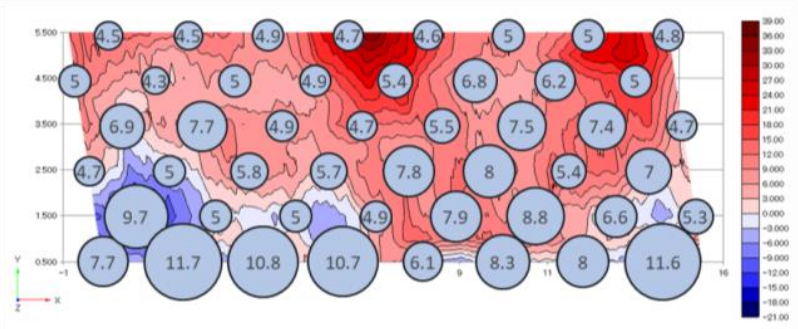

(b) at 15:00

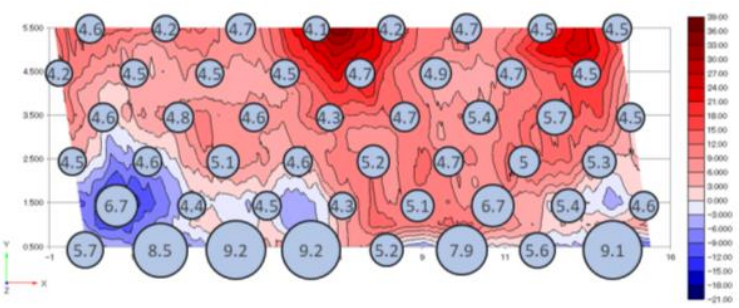

(c) at 15:45

Fig. 14. Change of surface water content and slab surface shape

design longitudinal gradient (Table 3). However, because there are irregularities on the line, it seems that it causes local water stagnation.

There are multiple places where the water content is larger than the surroundings in all three measurements. This means that there is a part where stagnant water is likely to occur locally. This is consistent with the fact that local wetting points are confirmed in the observation of the surface of the slab after sprinkling (Fig. 10).

In the photograph, it is also understood that the back is the kerb, and it is found that the water is stagnating around the kerb.

\subsection{Relationship between surface shape and water stagnation}

From the above, there is a tendency for local water stagnation to occur, so the relationship with the surface shape is considered specifically. Fig. 14 shows the measured values of water content in bubbles with the surface shape of Fig. 11 superimposed.

From this figure, it can be seen that the water content in the concave portion is higher than in other portions. The water content of the concave portion decreases with the lapse of time, but the remaining position does not change. Therefore, it can be understood that the decrease in the water content is due to evaporation, not due to drainage by the gradient. Also, at the convex portion, the water content is lower than that of the surrounding area. In addition, there is a portion where the water content is high at the upper part of the slope of the convex portion, which means that the convex portion hinders the drainage. The above shows that irregularities on the surface of the slab surface cause local water stagnation. There are also parts where water content is not so high in concave portions. This is considered to be because relatively shallow depressions do not hinder water drainage because of the design gradient.

\section{Conclusions}

This study aims to understand the unevenness of the slab surface before the waterproof layer is constructed. This is a state without waterproof layer and pavement, therefore it does not necessarily indicate the state of an actual bridge. Though, it has been confirmed that there is a relationship between local stagnant water observed on the slab and the surface shape of the slab.

In this study, we focused on irregularities on the slab surface and observed the state of water stagnation. It has been found that whether or not water stagnation occurs on the surface of the slab depends not only on the unevenness, but also on the magnitude of the longitudinal and transverse gradient.

Since this study investigated only one bridge, it is early to conclude the evaluation on the influence of the gradient. In order to investigate the general relationship between the surface shape and the tendency of water stagnation in detail, it is necessary to conduct a survey with a number of bridges and compare the results.

Although it is ideal to flatten the construction surface completely as designed, it is not realistic. On the assumption that unevenness will occur, it is necessary to investigate to what extent the undulation can be accepted when constructing the gradient. Based on such a study, it will be a future task to study irregularities management method that does not inhibit drainage function.

\section{References}

1. Japan Road Association: Explanation and Operation of Road Structure Ordinance (2015)

2. Japan Road Association: Handbook for Waterproof Roadway Bridge Deck Slabs (2007) 